\title{
Ten-year resistance trends in pathogens causing healthcare-associated infections; reflection of infection control interventions at a multi-hospital healthcare system in Saudi Arabia, 2007-2016
}

\author{
Hanan H. Balkhy ${ }^{1,2,3^{*}}$, Aiman El-Saed ${ }^{1,2,4}$, Majid M. Alshamrani ${ }^{1,2}$, Asim Alsaedi ${ }^{5}$, Wafa Al Nasser ${ }^{6}$, \\ Ayman El Gammal ${ }^{7}$, Sameera M. Aljohany, ${ }^{2,8}$, Sara Almunif', Yassen Arabi ${ }^{2,9}$, Saad Alqahtani ${ }^{2,9}$, \\ Henry Baffoe Bonnie ${ }^{1,2}$, Majed Alghoribi ${ }^{2,3}$, Adel Alothman ${ }^{2,10}$ and Saad A. Almohrii ${ }^{2,11}$
}

\begin{abstract}
Background: Studying temporal changes in resistant pathogens causing healthcare-associated infections (HAls) is crucial in improving local antimicrobial and infection control practices. The objective was to describe ten-year trends of resistance in pathogens causing HAls in a tertiary care setting in Saudi Arabia and to compare such trends with those of US National Health Surveillance Network (NHSN).

Methods: Pooled analysis of surveillance data that were prospectively collected between 2007 and 2016 in four hospitals of Ministry of National Guard Health Affairs. Definitions and methodology of HAls and antimicrobial resistance were based on NHSN. Consecutive NHSN reports were used for comparisons.

Results: A total 1544 pathogens causing 1531 HAl events were included. Gram negative pathogens (GNP) were responsible for $63 \%$ of HAls, with a significant increasing trend in Klebsiella spp. and a decreasing trend in Acinetobacter. Methicillin-resistant Staphylococcus aureus (27.0\%) was consistently less frequent than NHSN. Vancomycin-resistant Enterococci (VRE, 20.3\%) were more than doubled during the study, closing the gap with NHSN. Carbapenem resistance was highest with Acinetobacter (68.3\%) and Pseudomonas (36.8\%). Increasing trends of carbapenem resistance were highest in Pseudomonas and Enterobacteriaceae, closing initial gaps with NHSN. With the exception of Klebsiella and Enterobacter, multidrug-resistant (MDR) GNPs were generally decreasing, mainly due to the decreasing resistance towards cephalosporins, fluoroquinolones, and aminoglycosides.

Conclusion: The findings showed increasing trends of carbapenem resistance and VRE, which may reflect heavy use of carbapenems and vancomycin. These findings may highlight the need for effective antimicrobial stewardship programs, including monitoring and feedback on antimicrobial use and resistance.
\end{abstract}

Keywords: Antimicrobial resistance, Multidrug resistance, Healthcare-associated infections, Temporal trends, Hospital, Surveillance, Saudi Arabia

\footnotetext{
* Correspondence: balkhyh@ngha.med.sa; balkhyh@ngha.med.sa

${ }^{1}$ Infection Prevention and Control Department, King Abdulaziz Medical City

(KAMC), Ministry of National Guard Health Affairs (MNGHA), Riyadh, Saudi

Arabia

${ }^{2}$ King Saud bin Abdulaziz University for Health Sciences, Riyadh, Saudi Arabia

Full list of author information is available at the end of the article
}

(c) The Author(s). 2020 Open Access This article is distributed under the terms of the Creative Commons Attribution 4.0 International License (http://creativecommons.org/licenses/by/4.0/), which permits unrestricted use, distribution, and reproduction in any medium, provided you give appropriate credit to the original author(s) and the source, provide a link to the Creative Commons license, and indicate if changes were made. The Creative Commons Public Domain Dedication waiver (http://creativecommons.org/publicdomain/zero/1.0/) applies to the data made available in this article, unless otherwise stated. 


\section{Introduction}

Healthcare-associated infections (HAIs) are associated with a considerable increase in morbidity, mortality, length of stay, disability, and healthcare cost [1-3]. These are believed to be further worsened by involvement of resistant pathogens, specially multi-drug resistant (MDR) ones [4-6]. Unfortunately, the contribution of resistant pathogens to HAIs is probably mounting in both increasing and decreasing infection settings [7, 8]. Studying the temporal changes of resistant pathogens responsible for documented HAIs is crucial in understanding the local epidemiology of HAI and improving local antimicrobial and infection control practices [9]. These trends are probably reflecting several interplaying practices/factors such as antimicrobial consumption [10, 11], infection control practices [12], environmental cleaning [13], and community burden [14].

The Infection Prevention and Control (IPC) department at Ministry of National Guard Health Affairs (MNGHA) Riyadh is serving as the hub for the Gulf Corporate Council (GCC) Center for Infection Control and the World Health Organization (WHO) Collaborating Center for IPC and antimicrobial resistance. The ICP department has been conducting focused surveillance in affiliated hospitals, based on the National Health Surveillance Network (NHSN) methods. Additionally, it has developed and is regularly updating a surveillance manual to standardize HAI definitions, data collection forms, and surveillance methods in the MNGHA hospitals and GCC member countries. Furthermore, surveillance data are centrally analyzed to provide regular standardized reports and publications. To date, the IPC department has published three benchmarking reports covering device-associated HAIs (DA-HAIs) in MNGHA and GCC hospitals [15-17]. Unfortunately, these reports were lacking information on resistance patterns of pathogens causing HAIs and their changes overtime. Moreover, such data are lacking regionally and limited internationally. The objective of the current study was to describe ten-year resistance trends in pathogens causing HAIs using the surveillance data collected from four MNGHA hospitals. Additionally, to compare such trends with corresponding trends in published NHSN report.

\section{Methods}

\section{Setting}

The surveillance datasets for four MNGHA affiliated hospitals were analyzed in this report. MNGHA hospitals are governmentally funded tertiary care hospitals that provide services for more than 1.5 million Saudi National Guard soldiers, employees and their families. The total bed capacity is 2200 beds with approximately $10 \%$ allocated for critical care services. Outpatient dialysis units include approximately 66 chairs used by more than 400 patients monthly. Approximately 30 thousands surgical procedures are performed in MNGHA hospitals every year. All hospitals are accredited by Joint Commission International (JCI). More details of MNGHA hospitals are shown in Additional file 1: Table S1.

\section{The ICP program at MNGHA hospitals}

The ICP program is composed of an independent IPC department at each hospital that reports to the corporate ICP department in Riyadh. The latter ensure comparable practices and surveillance activities in all hospitals. The program is run by 24 infection preventionists; typically nurses with 2 years of infection training with or without CIBC certification (Additional file 1: Table S1). Each IPC department tailors its focused/targeted surveillance plan based on a local annual risk assessment that is approved by the IPC committee. Details of the IPC program activities to mitigate HAIs are shown in Additional file 1: Figure $\mathrm{S} 1$.

\section{Design}

Pooled analysis of surveillance data that were prospectively collected between 2007 and 2016, using unified data collection forms and methods, adopted from the US NHSN [18].

\section{Infection and resistance definitions}

HAIs included; central line-associated bloodstream infection (CLABSI), ventilator-associated pneumonia (VAP), catheter-associated urinary tract infections (CAUTI), dialysis access-related bloodstream infections (ARBSI), and surgical site infection (SSI). The surveillance definitions and data collection methods were based on the NHSN definitions, including the changes introduced in 2011 and 2013 [19]. While rare, more than one pathogen was allowed for a single HAI event. MDR definitions were retrospectively calculated as per the current NHSN definitions [20] and recent NHSN reports [21, 22]. Cephalosporin-resistant Klebsiella was defined as Klebsiella testing non-susceptible (resistant or intermediate) to at least one cephalosporin agent (ceftazidime, cefotaxime, ceftriaxone, or cefepime) [20]. Carbapenem-resistant Enterobacteriaceae (CRE) was defined as Klebsiella, Escherichia coli, or Enterobacter testing resistant to imipenem [20]. MDR gram negative pathogens (GNPs) were defined as pathogens testing non-susceptible (resistant or intermediate) to at least one agent in at least 3 out of 5 antimicrobial classes; aminoglycosides (amikacin or gentamicin), cephalosporins (ceftazidime, cefotaxime, ceftriaxone, or cefepime), fluoroquinolones (ciprofloxacin or levofloxacin), carbapenems (imipenem or meropenem), $\beta$-lactamase inhibitor (piperacillin or piperacillin/tazobactam) [21, 22]. Only in MDR Pseudomonas, 2 cephalosporins (cefepime 
and ceftazidime) rather than 4 cephalosporins (above) were considered.

\section{Event eligibility}

All laboratory confirmed HAI events detected between 2007 and 2016 were initially included. Therefore, SSI, VAP, and neonatal "clinical sepsis" that were clinically diagnosed without laboratory confirmation were excluded. CAUTI events that are no longer meeting the latest definition (such as asymptomatic bacteriuria and fungal CAUTI) were excluded to allow more relevance of the study findings to current practices. Finally, HAI events lacking pathogen information were also excluded.

\section{Statistical methods}

Categorical variables were presented as frequencies and percentages while continuous variables were presented as means and standard deviations. Age and gender were calculated for non-duplicate patients only. The distribution of pathogens and their resistance were presented overtime. The difference was examined using Mantel Haenszel Chi Square for linear trend. Two-year periods rather than one-year was chosen to allow for bigger number of events and consequently more reliable percentages. Trends of pathogen distribution and resistance were compared to corresponding trends in NHSN hospitals $[21,22]$. HAI data in NHSN reports were combined and averaged per our study assigned time periods. Since 2007-2008 NHSN report provided only percentages, the average of all HAI events could not be estimated and was replaced by CLABSI percentages. SPSS (Version 25.0. Armonk, NY: IBM Corp) was used for all statistical analyses.

\section{Results}

\section{HAl events and patients}

Out of 2012 pathogens, 1544 pathogens linked to 1531 HAI events in 1333 patients were included. A total of 468 pathogens from 465 HAI events were excluded. These included 326 HAIs clinically diagnosed without laboratory confirmation; 197 SSI, 111 VAP, and 18 neonatal "clinical sepsis". Additionally, 102 CAUTI with older criteria of diagnosis and 38 deviceassociated HAI with missing microbiological data were excluded. Details of included HAIs by hospital and hospital locations are shown in Additional file 1: Table S1. Approximately $52.8 \%$ of patients with included pathogens were females and the average age was $43.4 \pm 27.0$ years $(79.1 \%$ adult patients and $20.9 \%$ pediatric/neonatal patients).

\section{Trends of causative pathogens}

As shown in Table 1, GNPs were the most common (63.0\%), followed by gram positive-pathogens (GPPs,
31.6\%) and fungi (5.4\%). The ranking in a decreasing order were: Pseudomonas (15.4\%), Klebsiella (14.7\%), Staphylococcus aureus (13.9\%), Enterobacter (9.1\%), and lastly Escherichia coli (9.1\%). Among all pathogens, Klebsiella was the only pathogen to show a significant increasing trend during the study periods ( $p$-value for trend $=0.016$ ) while Acinetobacter was the only pathogen to show a significant decreasing trend during the study periods ( $p$-value for trend $=0.009$ ). The other pathogens tended to be stable during the study periods. Enterobacter and Escherichia coli showed slight but nonsignificant increase by the end of the study ( 2.2 and $1.3 \%$, respectively) while Enterococcus and Coagulase negative staphylococci showed slight but non-significant decrease by the end of the study $(-1.6 \%$ and $-1.4 \%$, respectively).

\section{Trends of resistant pathogens}

The trends of antimicrobial resistance in different pathogens overtime are shown in Table 2. Overall, approximately $25 \%$ of both GPPs and GNPs had some type of resistance during the study. The most resistant pathogens were MDR Stenotrophomonas (70.0\%), MDR Acinetobacter (64.1\%), cephalosporin-resistant Klebsiella (32.1\%), and methicillin-resistant Staphylococcus aureus (MRSA, 27.0\%). CRE was significantly increasing from 0.0 to $11.4 \%$ ( $p$-value for trend $=0.004)$. This was statistically evident in carbapenem-resistant Escherichia coli from 0.0 to $12.5 \%$ ( $p$-value for trend $=0.007$ ) and to less extent in carbapenem-resistant Klebsiella from 0.0 to $15.4 \%$ ( $p$-value for trend $=0.066$ )

Overall GPP and GNP resistance by the type of HAI are shown in Fig. 1. Device-associated HAIs were presented as one group, as the small number of VAP and CAUTI did not allow breaking done the trends by the type of HAI and organisms combined. GPP resistance showed big variations overtime with a generally increased resistance in dialysis ARBSI and decreased resistance in SSI; none of which was statistically significant. On the other hand, GNP resistance showed a slight decreased resistance in device-associated HAI and dialysis ARBSI, also none were statistically significance (0.066 and 0.084, respectively).

More details regarding the trends of resistance for specific antimicrobial classes in GNPs are provided in Table 3 . For all GNPs combined, there were relative decreases in the resistance against aminoglycosides (31.6\%), cephalosporins (26.4\%), fluoroquinolones (16.6\%), and b-lactam $(12.2 \%)$ but $82.7 \%$ relative increase in the resistance against carbapenems by the end of the study. Carbapenem resistance was highest with Acinetobacter (68.3\%) and Pseudomonas (36.8\%). The increase in carbapenem resistance was highest in Pseudomonas (2.5 folds increase), increasing in Klebsiella and Escherichia coli (from zero to 


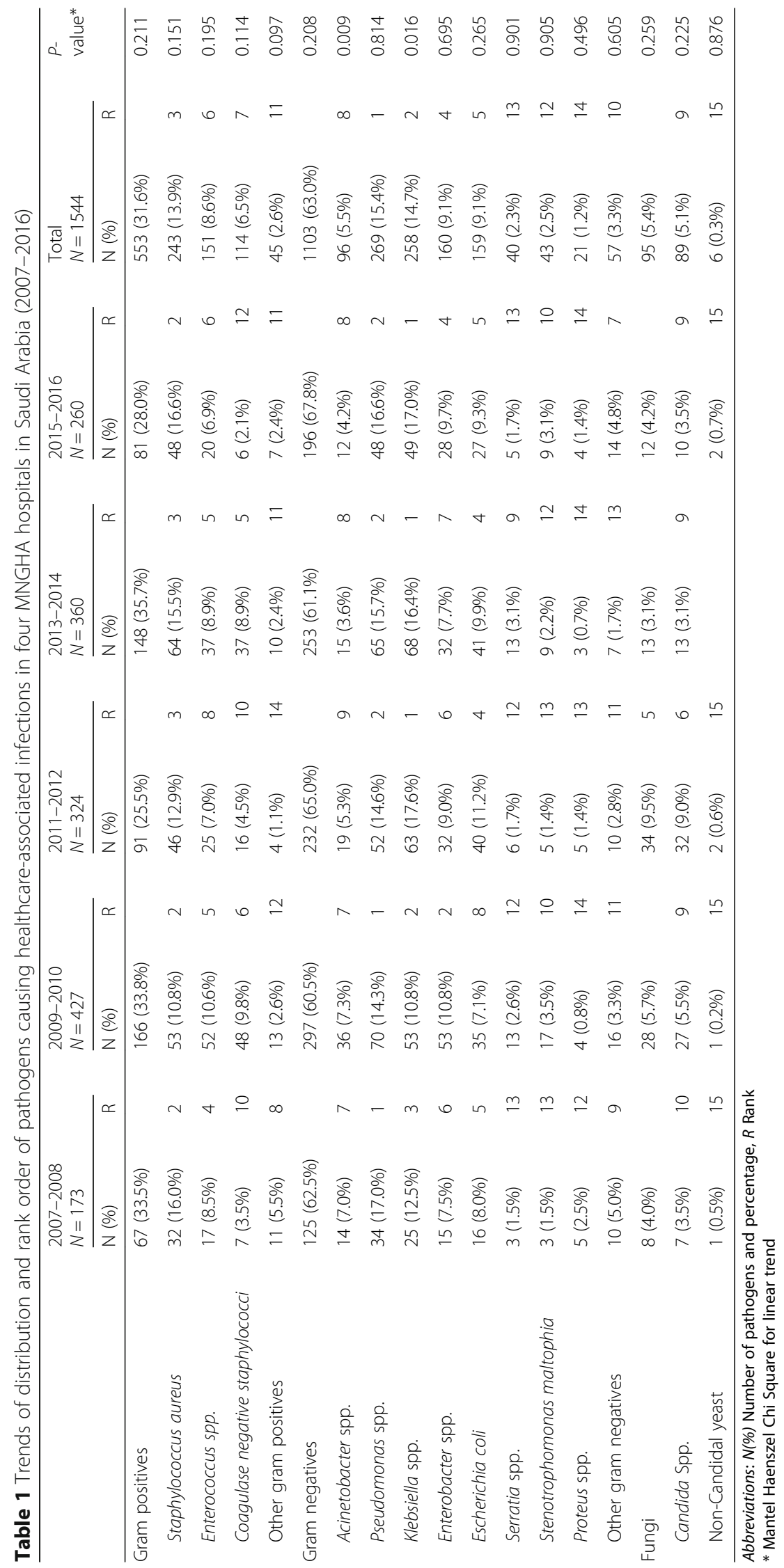




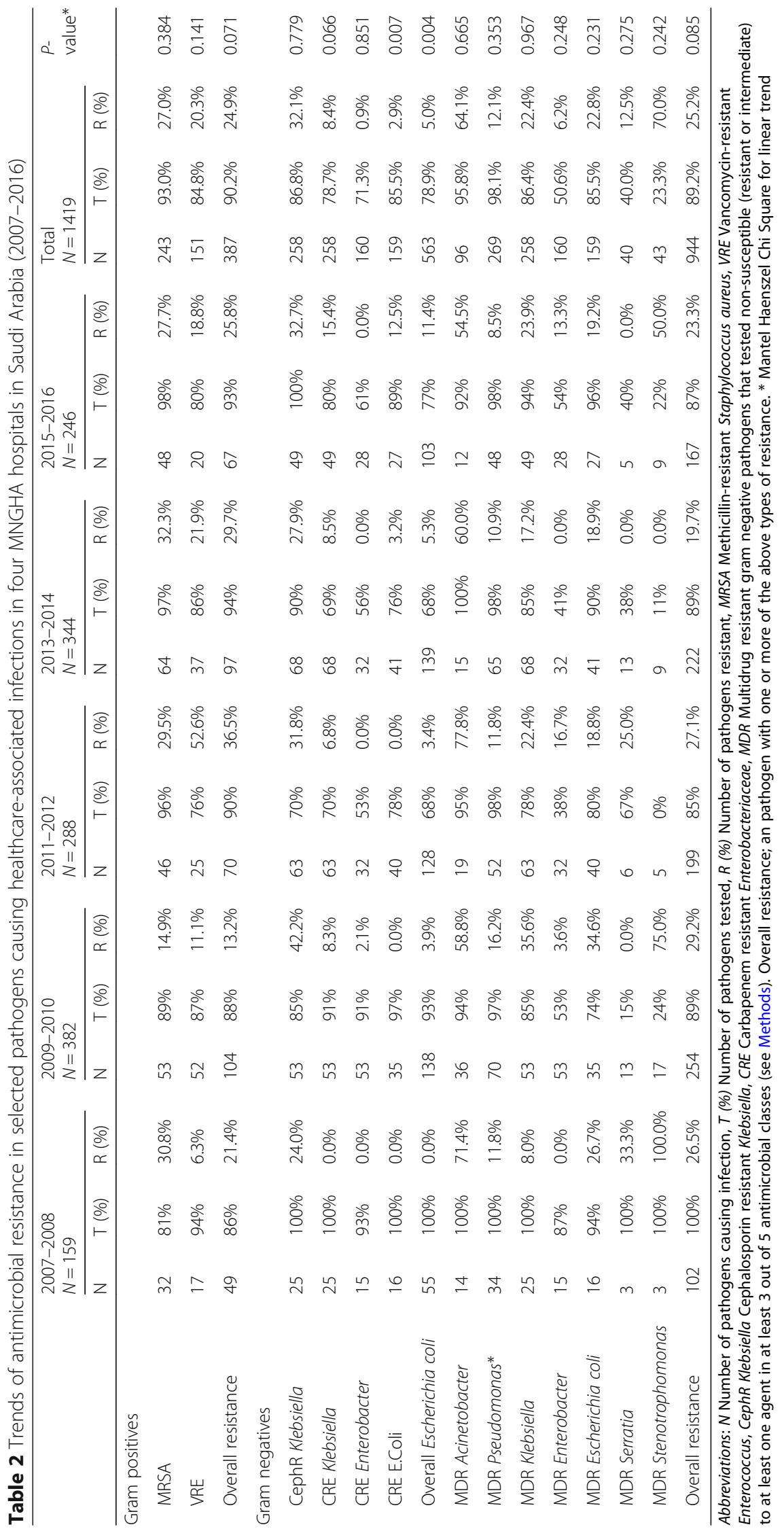




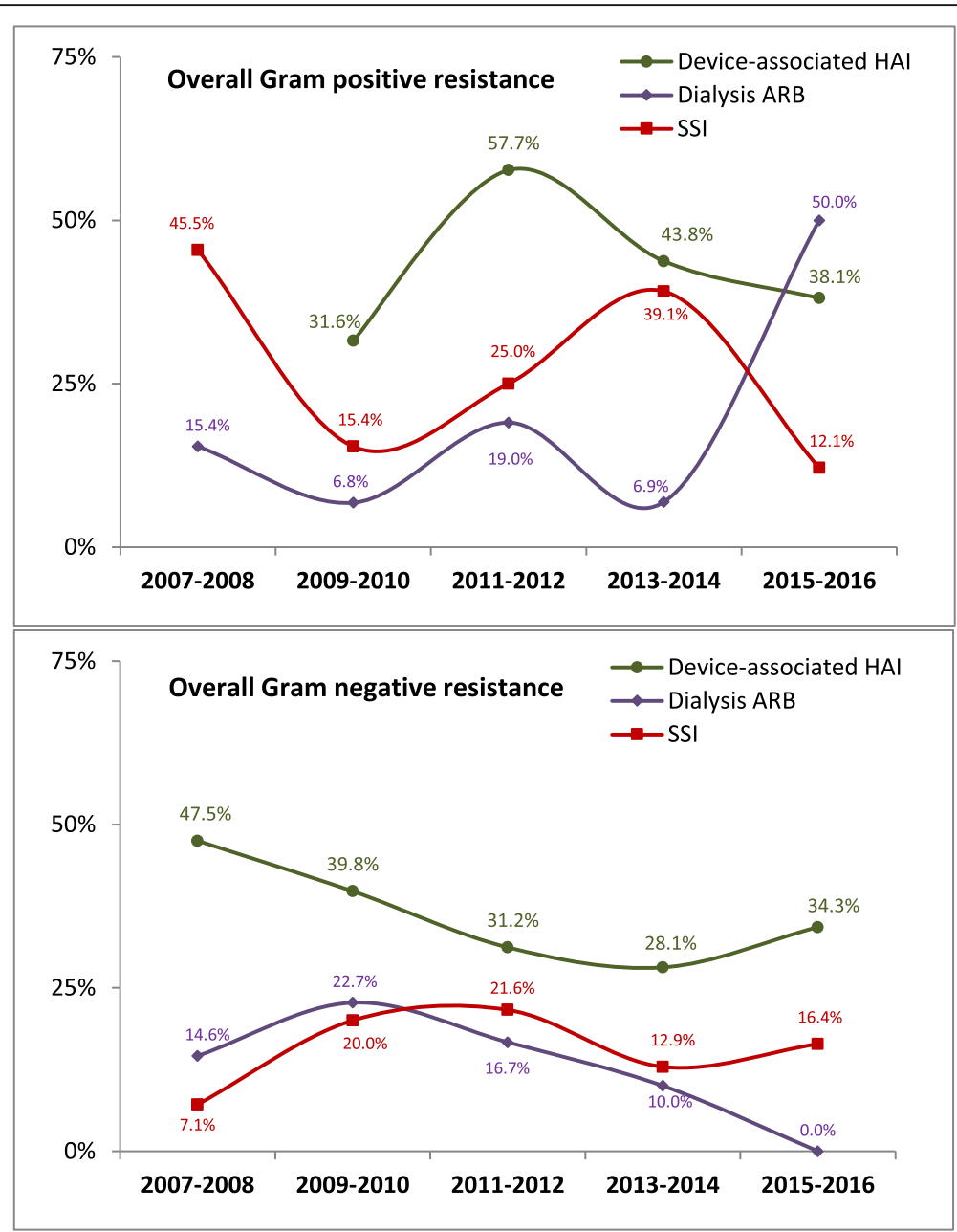

Fig. 1 Trends of overall resistance of pathogens causing healthcare-associated infections by type of infection in four MNGHA hospitals in Saudi Arabia (2007-2016). Note: Gram positive resistance includes MRSA or VRE. Gram negative resistance include CephR Klebsiella, CRE, MDR Acinetobacter, MDR Pseudomonas, MDR Klebsiella, MDR Escherichia coli, MDR Serratia, or MDR Stenotrophomonas, as shown in Table 2. Deviceassociated HAl included central line-associated bloodstream infection, ventilator-associated pneumonia, and catheter-associated urinary tract infection

33.3 and $15.8 \%$, respectively), and non-existent in Enterobacter. Klebsiella was the only pathogen to show an increased resistance against all tested classes while Acinetobacter was the only pathogen to show a decreased resistance against all tested classes.

\section{Comparisons with NHSN trends of resistant pathogens}

The trends of antimicrobial resistance in MNGHA compared with NHSN hospitals are shown in Fig. 2. The NHSN data points are up to year 2014 due to a lack of updated NHSN publication. MRSA was consistently less frequent in MNGHA than NHSN hospitals. VRE was more than doubled in MNGHA during the study closing the gap with NHSN hospitals. In Escherichia coli and Klebsiella, carbapenem resistance was increasing in MNGHA closing initial gaps with NHSN hospitals while cephalosporin-resistance and MDR were generally higher in MNGHA compared with NHSN hospitals. In Acinetobacter and Pseudomonas, carbapenem resistance was generally higher while MDR was generally comparable in MNGHA compared with NHSN hospitals.

\section{Discussion}

The current report showed 10-year trends of the distribution and resistance of pathogens causing the five most commonly surveyed HAIs. The most interesting finding in the current study was the increasing contribution and resistance of Enterobacteriaceae. For example, the contribution of Enterobacteriaceae to HAIs increased from 28 to $33 \%$ during the study with concomitant emergence of CRE from 0 to 5\%. Klebsiella spp. was the major component of CRE. Historically, 
Table 3 Trends of resistance to specific antimicrobial classes in gram negative pathogens causing healthcare-associated infections in four MNGHA hospitals in Saudi Arabia (2007-2016)

\begin{tabular}{|c|c|c|c|c|c|c|c|c|}
\hline & \multirow{2}{*}{$\begin{array}{l}2007- \\
2008 \\
N=113\end{array}$} & \multirow{2}{*}{$\begin{array}{l}2009- \\
2010 \\
N=268\end{array}$} & \multirow{2}{*}{$\begin{array}{l}2011- \\
2012 \\
N=212\end{array}$} & \multirow{2}{*}{$\begin{array}{l}2013-2014 \\
N=232\end{array}$} & \multirow{2}{*}{$\begin{array}{l}2015- \\
2016 \\
N=180\end{array}$} & \multirow{2}{*}{$\begin{array}{l}\text { Total } \\
N=1005\end{array}$} & \multicolumn{2}{|l|}{ Change* $^{*}$} \\
\hline & & & & & & & Absolute & Relative \\
\hline \multicolumn{9}{|l|}{ Acinetobacter } \\
\hline Aminoglycosides & $10(71.4 \%)$ & $16(45.7 \%)$ & 8 (44.4\%) & 7 (46.7\%) & $6(50.0 \%)$ & 47 (50.0\%) & $-21.4 \%$ & $-30.0 \%$ \\
\hline B-lactam & 10 (76.9\%) & $14(58.3 \%)$ & 10 (90.9\%) & $6(54.5 \%)$ & $6(75.0 \%)$ & 46 (68.7\%) & $-1.9 \%$ & $-2.5 \%$ \\
\hline Carbapenems & $10(71.4 \%)$ & $17(63.0 \%)$ & $13(81.3 \%)$ & $10(66.7 \%)$ & $6(60.0 \%)$ & $56(68.3 \%)$ & $-11.4 \%$ & $-16.0 \%$ \\
\hline Cephalosporins & $11(84.6 \%)$ & $22(66.7 \%)$ & $14(82.4 \%)$ & $13(100.0 \%)$ & 7 (70.0\%) & 67 (77.9\%) & $-14.6 \%$ & $-17.3 \%$ \\
\hline Fluoroquinolones & $10(71.4 \%)$ & $20(58.8 \%)$ & $14(77.8 \%)$ & $10(66.7 \%)$ & 7 (63.6\%) & 61 (66.3\%) & $-7.8 \%$ & $-10.9 \%$ \\
\hline MDR3 & $10(71.4 \%)$ & 20 (58.8\%) & $14(77.8 \%)$ & $9(60.0 \%)$ & $6(54.5 \%)$ & 59 (64.1\%) & $-16.9 \%$ & $-23.6 \%$ \\
\hline MDR4 & $10(71.4 \%)$ & $18(52.9 \%)$ & 11 (61.1\%) & 7 (46.7\%) & $6(54.5 \%)$ & $52(56.5 \%)$ & $-16.9 \%$ & $-23.6 \%$ \\
\hline MDR5 & $8(57.1 \%)$ & 7 (20.6\%) & $5(27.8 \%)$ & $4(26.7 \%)$ & $6(54.5 \%)$ & 30 (32.6\%) & $-2.6 \%$ & $-4.5 \%$ \\
\hline \multicolumn{9}{|l|}{ Pseudomonas } \\
\hline Aminoglycosides & $6(18.2 \%)$ & 10 (14.9\%) & $6(11.8 \%)$ & 9 (13.8\%) & $3(6.3 \%)$ & 34 (12.9\%) & $-11.9 \%$ & $-65.6 \%$ \\
\hline B-lactam & 9 (30.0\%) & 15 (25.0\%) & $2(5.4 \%)$ & 19 (30.6\%) & $8(18.2 \%)$ & $53(22.7 \%)$ & $-11.8 \%$ & $-39.4 \%$ \\
\hline Carbapenems & $5(15.2 \%)$ & $11(42.3 \%)$ & $8(40.0 \%)$ & $9(50.0 \%)$ & $9(52.9 \%)$ & $42(36.8 \%)$ & $37.8 \%$ & $249.4 \%$ \\
\hline Cephalosporins* & $12(35.3 \%)$ & $24(36.4 \%)$ & $6(12.8 \%)$ & 9 (15.0\%) & $4(9.3 \%)$ & 55 (22.0\%) & $-26.0 \%$ & $-73.6 \%$ \\
\hline Fluoroquinolones & $2(5.9 \%)$ & $11(16.4 \%)$ & 7 (13.7\%) & $9(14.8 \%)$ & $5(10.9 \%)$ & 34 (13.1\%) & $5.0 \%$ & $84.8 \%$ \\
\hline MDR3 & $4(11.8 \%)$ & $11(16.2 \%)$ & $6(11.8 \%)$ & 7 (10.9\%) & $4(8.5 \%)$ & $32(12.1 \%)$ & $-3.3 \%$ & $-27.7 \%$ \\
\hline MDR4 & $2(5.9 \%)$ & $8(11.8 \%)$ & $4(7.8 \%)$ & $6(9.4 \%)$ & $2(4.3 \%)$ & $22(8.3 \%)$ & $-1.6 \%$ & $-27.7 \%$ \\
\hline MDR5 & $1(2.9 \%)$ & $4(5.9 \%)$ & $1(2.0 \%)$ & $5(7.8 \%)$ & $2(4.3 \%)$ & 13 (4.9\%) & $1.3 \%$ & $44.7 \%$ \\
\hline \multicolumn{9}{|l|}{ Klebsiella } \\
\hline Aminoglycosides & 7 (28.0\%) & $24(46.2 \%)$ & $20(32.8 \%)$ & $16(24.6 \%)$ & 15 (32.6\%) & 82 (32.9\%) & $4.6 \%$ & $16.5 \%$ \\
\hline B-lactam & $3(17.6 \%)$ & $14(50.0 \%)$ & $10(37.0 \%)$ & $14(31.8 \%)$ & $15(40.5 \%)$ & 56 (36.6\%) & $22.9 \%$ & $129.7 \%$ \\
\hline Carbapenems & $0(0.0 \%)$ & $4(13.3 \%)$ & $3(11.5 \%)$ & $4(14.3 \%)$ & $6(33.3 \%)$ & 17 (13.9\%) & $33.3 \%$ & - \\
\hline Cephalosporins & $6(27.3 \%)$ & 19 (63.3\%) & $14(48.3 \%)$ & 17 (34.7\%) & 16 (43.2\%) & 72 (43.1\%) & $16.0 \%$ & $58.6 \%$ \\
\hline Fluoroquinolones & $4(18.2 \%)$ & $21(46.7 \%)$ & 19 (33.9\%) & $12(18.5 \%)$ & $11(24.4 \%)$ & 67 (28.8\%) & $6.3 \%$ & $34.4 \%$ \\
\hline MDR3 & $2(8.0 \%)$ & $16(35.6 \%)$ & $11(22.4 \%)$ & 10 (17.2\%) & 11 (23.9\%) & $50(22.4 \%)$ & $15.9 \%$ & $198.9 \%$ \\
\hline MDR4 & 2 (8.0\%) & $5(11.1 \%)$ & $3(6.1 \%)$ & 7 (12.1\%) & 7 (15.2\%) & $24(10.8 \%)$ & $7.2 \%$ & $90.2 \%$ \\
\hline MDR5 & $0(0.0 \%)$ & $1(2.2 \%)$ & $0(0.0 \%)$ & $2(3.4 \%)$ & 5 (10.9\%) & $8(3.6 \%)$ & $10.9 \%$ & - \\
\hline \multicolumn{9}{|l|}{ Enterobacte } \\
\hline Aminoglycosides & $0(0.0 \%)$ & 7 (14.0\%) & $2(6.7 \%)$ & $5(16.7 \%)$ & $2(7.1 \%)$ & $16(10.5 \%)$ & $7.1 \%$ & - \\
\hline B-lactam & $2(50.0 \%)$ & $5(22.7 \%)$ & $3(37.5 \%)$ & $1(50.0 \%)$ & $2(50.0 \%)$ & 13 (32.5\%) & $0.0 \%$ & $0.0 \%$ \\
\hline Carbapenems & $0(0.0 \%)$ & $1(6.7 \%)$ & $0(0.0 \%)$ & $0(0.0 \%)$ & $0(0.0 \%)$ & $1(1.6 \%)$ & $0.0 \%$ & - \\
\hline Cephalosporins & $2(50.0 \%)$ & $10(52.6 \%)$ & $3(50.0 \%)$ & $2(33.3 \%)$ & $5(55.6 \%)$ & $22(50.0 \%)$ & $5.6 \%$ & $11.1 \%$ \\
\hline Fluoroquinolones & $0(0.0 \%)$ & $4(8.7 \%)$ & $2(6.7 \%)$ & $0(0.0 \%)$ & $3(10.7 \%)$ & 9 (6.1\%) & $10.7 \%$ & - \\
\hline MDR3 & $0(0.0 \%)$ & $1(3.6 \%)$ & $2(16.7 \%)$ & $0(0.0 \%)$ & $2(13.3 \%)$ & $5(6.2 \%)$ & $13.3 \%$ & - \\
\hline MDR4 & $0(0.0 \%)$ & $0(0.0 \%)$ & $1(8.3 \%)$ & $0(0.0 \%)$ & $0(0.0 \%)$ & $1(1.2 \%)$ & $0.0 \%$ & - \\
\hline MDR5 & $0(0.0 \%)$ & $0(0.0 \%)$ & $0(0.0 \%)$ & $0(0.0 \%)$ & $0(0.0 \%)$ & $0(0.0 \%)$ & $0.0 \%$ & - \\
\hline \multicolumn{9}{|l|}{ Escherichia coli } \\
\hline Aminoglycosides & $5(31.3 \%)$ & $14(40.0 \%)$ & $14(35.0 \%)$ & 12 (31.6\%) & $9(34.6 \%)$ & $54(34.8 \%)$ & $3.4 \%$ & $10.8 \%$ \\
\hline B-lactam & $5(45.5 \%)$ & $6(28.6 \%)$ & $5(35.7 \%)$ & $6(23.1 \%)$ & $9(60.0 \%)$ & 31 (35.6\%) & $14.5 \%$ & $32.0 \%$ \\
\hline Carbapenems & $0(0.0 \%)$ & $0(0.0 \%)$ & $0(0.0 \%)$ & $1(4.8 \%)$ & $3(15.8 \%)$ & $4(4.4 \%)$ & $15.8 \%$ & - \\
\hline Cephalosporins & $10(66.7 \%)$ & $10(45.5 \%)$ & $14(56.0 \%)$ & 17 (47.2\%) & $14(53.8 \%)$ & 65 (52.4\%) & $-12.8 \%$ & $-19.2 \%$ \\
\hline Fluoroquinolones & $7(46.7 \%)$ & $13(38.2 \%)$ & $18(51.4 \%)$ & 18 (46.2\%) & $9(36.0 \%)$ & 65 (43.9\%) & $-10.7 \%$ & $-22.9 \%$ \\
\hline
\end{tabular}


Table 3 Trends of resistance to specific antimicrobial classes in gram negative pathogens causing healthcare-associated infections in four MNGHA hospitals in Saudi Arabia (2007-2016) (Continued)

\begin{tabular}{|c|c|c|c|c|c|c|c|c|}
\hline & \multirow{2}{*}{$\begin{array}{l}2007- \\
2008 \\
N=113\end{array}$} & \multirow{2}{*}{$\begin{array}{l}2009- \\
2010 \\
N=268\end{array}$} & \multirow{2}{*}{$\begin{array}{l}2011- \\
2012 \\
N=212\end{array}$} & \multirow{2}{*}{$\begin{array}{l}2013-2014 \\
N=232\end{array}$} & \multirow{2}{*}{$\begin{array}{l}2015- \\
2016 \\
N=180\end{array}$} & \multirow{2}{*}{$\begin{array}{l}\text { Total } \\
N=1005\end{array}$} & \multicolumn{2}{|l|}{ Change* $^{*}$} \\
\hline & & & & & & & Absolute & Relative \\
\hline MDR3 & $4(26.7 \%)$ & $9(34.6 \%)$ & $6(18.8 \%)$ & 7 (18.9\%) & $5(19.2 \%)$ & 31 (22.8\%) & $-7.4 \%$ & $-27.9 \%$ \\
\hline MDR4 & $3(20.0 \%)$ & $1(3.8 \%)$ & $2(6.3 \%)$ & $3(8.1 \%)$ & $4(15.4 \%)$ & $13(9.6 \%)$ & $-4.6 \%$ & $-23.1 \%$ \\
\hline MDR5 & $0(0.0 \%)$ & $0(0.0 \%)$ & $0(0.0 \%)$ & $1(2.7 \%)$ & $0(0.0 \%)$ & $1(0.7 \%)$ & $0.0 \%$ & - \\
\hline \multicolumn{9}{|l|}{ Others* } \\
\hline Aminoglycosides & $5(50.0 \%)$ & 7 (25.9\%) & $1(11.1 \%)$ & $4(23.5 \%)$ & $2(16.7 \%)$ & 19 (25.3\%) & $-33.3 \%$ & $-66.7 \%$ \\
\hline B-lactam & 3 (42.9\%) & 2 (25.0\%) & 1 (33.3\%) & 2 (28.6\%) & 2 (28.6\%) & 10 (31.3\%) & $-14.3 \%$ & $-33.3 \%$ \\
\hline Carbapenems & $3(33.3 \%)$ & $9(56.3 \%)$ & $2(50.0 \%)$ & $2(40.0 \%)$ & $7(70.0 \%)$ & $23(52.3 \%)$ & $36.7 \%$ & $110.0 \%$ \\
\hline Cephalosporins & $5(55.6 \%)$ & 10 (52.6\%) & $2(33.3 \%)$ & $2(22.2 \%)$ & $4(40.0 \%)$ & 23 (43.4\%) & $-15.6 \%$ & $-28.0 \%$ \\
\hline Fluoroquinolones & $2(25.0 \%)$ & 7 (25.0\%) & 1 (11.1\%) & $3(16.7 \%)$ & $1(9.1 \%)$ & 14 (18.9\%) & $-15.9 \%$ & $-63.6 \%$ \\
\hline MDR3 & $4(40.0 \%)$ & $5(29.4 \%)$ & $1(16.7 \%)$ & 1 (9.1\%) & $2(22.2 \%)$ & $13(24.5 \%)$ & $-17.8 \%$ & $-44.4 \%$ \\
\hline MDR4 & $2(20.0 \%)$ & $2(11.8 \%)$ & $0(0.0 \%)$ & $1(9.1 \%)$ & $1(11.1 \%)$ & $6(11.3 \%)$ & $-8.9 \%$ & $-44.4 \%$ \\
\hline MDR5 & $2(20.0 \%)$ & $2(11.8 \%)$ & $0(0.0 \%)$ & $0(0.0 \%)$ & $1(11.1 \%)$ & $5(9.4 \%)$ & $-8.9 \%$ & $-44.4 \%$ \\
\hline \multicolumn{9}{|l|}{ Overall } \\
\hline Aminoglycosides & 32 (31.7\%) & 75 (31.5\%) & 48 (25.4\%) & $50(23.9 \%)$ & 34 (21.7\%) & 239 (26.7\%) & $-10.0 \%$ & $-31.6 \%$ \\
\hline B-lactam & 31 (41.9\%) & 54 (36.7\%) & $30(33.0 \%)$ & 45 (31.5\%) & 39 (36.8\%) & 199 (35.5\%) & $-5.1 \%$ & $-12.2 \%$ \\
\hline Carbapenems & 18 (19.4\%) & 39 (32.2\%) & $26(28.3 \%)$ & 25 (26.3\%) & 29 (35.4\%) & 137 (28.4\%) & $16.0 \%$ & $82.7 \%$ \\
\hline Cephalosporins & 48 (54.5\%) & 93 (54.1\%) & $52(42.6 \%)$ & $60(37.0 \%)$ & $51(40.2 \%)$ & 304 (45.3\%) & $-14.4 \%$ & $-26.4 \%$ \\
\hline Fluoroquinolones & 25 (26.0\%) & 73 (32.3\%) & 59 (32.8\%) & 48 (23.3\%) & 33 (21.7\%) & $238(27.7 \%)$ & $-4.3 \%$ & $-16.6 \%$ \\
\hline MDR3 & $23(23.0 \%)$ & 61 (31.4\%) & 39 (25.5\%) & 33 (18.4\%) & 28 (20.1\%) & 184 (24.1\%) & $-2.9 \%$ & $-12.4 \%$ \\
\hline MDR4 & 19 (19.0\%) & 34 (17.5\%) & $21(13.7 \%)$ & $23(12.8 \%)$ & 19 (13.7\%) & $116(15.2 \%)$ & $-5.3 \%$ & $-28.1 \%$ \\
\hline MDR5 & $11(11.0 \%)$ & $12(6.2 \%)$ & 6 (3.9\%) & $12(6.7 \%)$ & $12(8.6 \%)$ & $53(6.9 \%)$ & $-2.4 \%$ & $-21.5 \%$ \\
\hline
\end{tabular}

Abbreviations: Others include Serratia spp., Stenotrophomonas maltophia, Citrobacter spp., Proteus, and Providencia. MDR3, MDR4, MDR5 are multidrug resistant gram negative pathogens that non-susceptible (resistant or intermediate) to at least one agent in at least 3, 4, or 5 out of 5 antimicrobial classes (respectively). *Absolute change is the difference between 2015 and 2016 rate and 2007-2008 rate. Relative change is the proportion of absolute change relative to 2007-2008 rate

carbapenem-resistant Klebsiella pneumoniae (CRKP) started in the USA then spread to Israel and other Middle Eastern counties [23-25]. The first outbreak of CRKP in MNGHA facilities was documented in 2010 [26] and was caused by an outer membrane protein [27]. The active surveillance that was started in response to that outbreak could not eliminate the risk of CRKP which continued to be seen thereafter at a lower level. This may explain the big difference in CRE between MNGHA and NHSN at the beginning of the study and the gradual narrowing of that difference thereafter. Additionally, local and national efforts done in the USA to reduce the burden of CRKP/CRE at both hospital and community settings lead to a clear downtrend [28, 29]. With increasing trend of CRE at MNGHA, we may see flipping of the MNGHA traditional comparisons of CRE with the NHSN in the coming years. Several local/regional challenges may explain the worsening of CRKP in Saudi Arabia and probably across the Middle East; variability of resistance mechanisms [25, 30], large transfer of workforce and pilgrimage [31,32], and immature ASP practices [33].

Carbapenem resistance in the current study was highest in Acinetobacter and Pseudomonas, which exceeded NHSN figures [21], may reflect the local heavy use of carbapenems, which has been recently documented [34]. Emergence of novel resistant strains and increasing prevalence of high-risk clones has been suggested to explain the increasing carbapenem resistance in Pseudomonas in Saudi Arabia and GCC region [35]. Interestingly, Acinetobacter contribution to HAI and its carbapenem resistance were decreasing during the current study. The high Acinetobacter at the beginning of the study was caused by a documented outbreak of Acinetobacter-caused VAP [36, 37]. The outbreak triggered several interventions including a continuous active surveillance of Acinetobacter in MNGHA ICUs [36, 37].

With the exception of Klebsiella and Enterobacter, MDR gram negatives in the current study were generally 


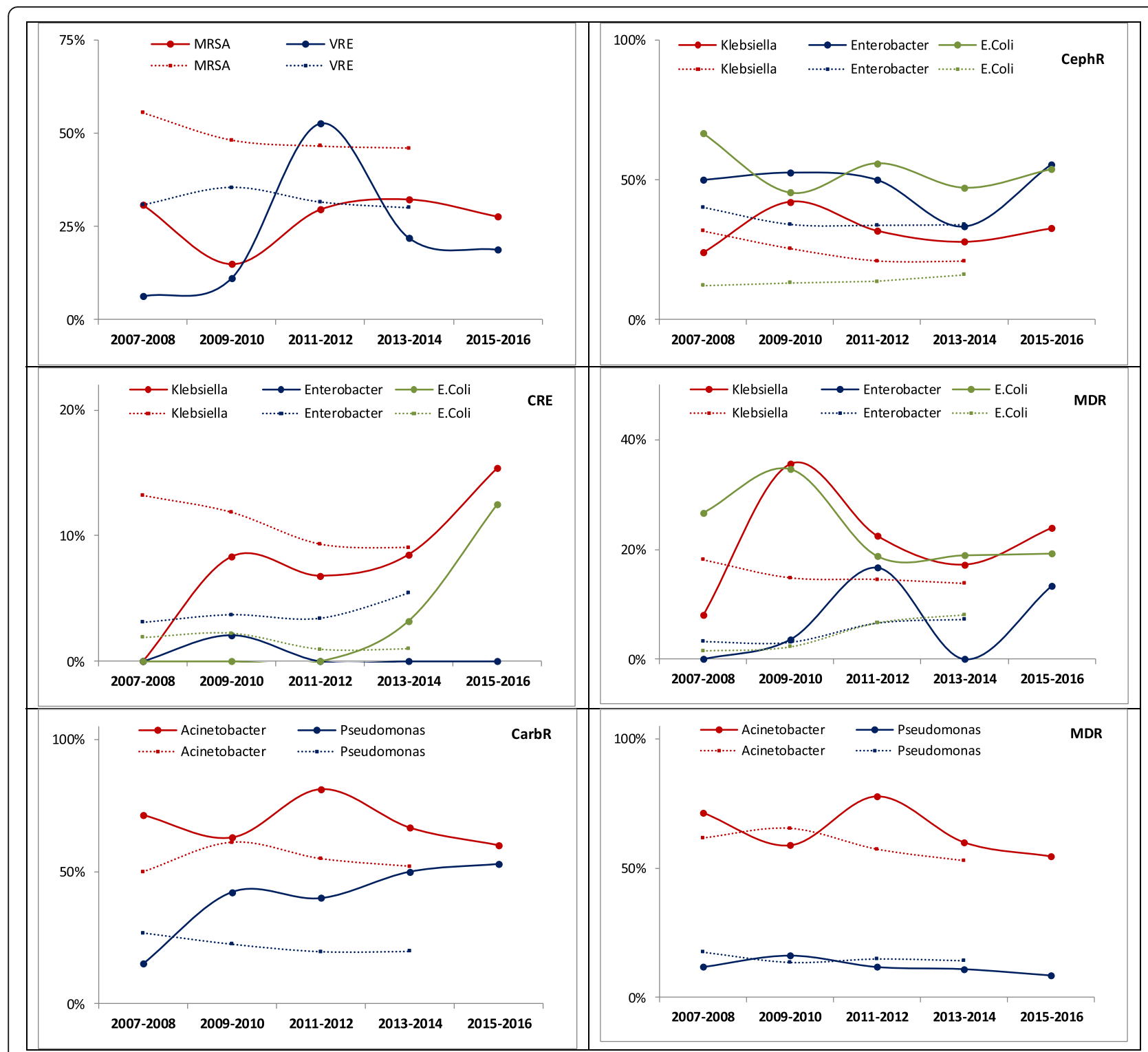

Fig. 2 Trends of antimicrobial resistance in pathogens causing healthcare-associated infections in in MNGHA hospitals (2007-2015) and NHSN hospitals (2007-2014). Abbreviations: As in Table 2. CephR, cephalosporin resistant; CarbR, carbapenem resistant. Solid lines represent pathogens causing all HAI in MNGHA while dotted lines represents pathogens causing CLABSI, VAP, CAUTI, and SSI compiled from the NHSN reports

decreasing, largely due to the decreasing resistance towards cephalosporins, fluoroquinolones, and aminoglycosides. Several efforts have been done in the last decade at MNGHA to reduce the burden of HAI and MDR; implementation of IHI preventive bundles for DA-HAIs $[17,38,39]$, structuring/reinforcing a multifaceted hand hygiene program, gradual shifting from patient cohorting to single room isolation, and staff training and certification in infection control. However, the main challenge remains to further support and enhance the newly launched ASP. Major obstacles that are being currently managed include the transfer from paper to electronic medical records and limited ASP team members available for guidance and auditing, specially clinical pharmacists and infectious diseases physicians.

As expected, there was an increasing VRE trend but stable or slightly decreasing MRSA trend during the study (both did not reach significant levels through) [40, 41]. Traditional low rates of VRE in Saudi Arabia have been challenged in the last decade with increasing and novel resistance patterns [40,42]. The increasing VRE trend during the study closed the gap initially observed between MNGHA and NHSN hospitals. These have been linked to extensive antimicrobial use in Saudi 
Arabia [43], including the ones on the top of the antimicrobial use list in our ICUs such vancomycin and piperacillin/tazobactam [34].

The current study was based on a large amount of data over a relatively long period of time which enabled us to monitor minor changes in antimicrobial resistance in several pathogens, which has not been matched in the region. The samples represented nonduplicate pathogens directly linked to the diagnosis of HAIs rather than unverified laboratory samples. Although a multi-hospital study, the data is considered very homogenous as the MNGHA hospitals share the same organizational structure, surveillance methodology, training, resources, and major related infection control interventions throughout the study period. For example, structuring/reinforcing multifaceted hand hygiene program, implementing the Institute for Healthcare Improvement (IHI) preventive bundles, and starting a stepwise antimicrobial stewardship program (ASP) all were done in comparable efforts during the same times. Nevertheless, the current data represented a scatter rather than comprehensive list of all HAIs during the study period due to two reasons; the targeted surveillance methodology and clinical diagnosis of some HAI. Yet, both were strictly done as per standard NHSN recommendations. Additionally, it would be better to have separate resistance trends for different HAIs. However, the small number of some HAIs made it impossible to break done the trends by the type of HAI and organisms combined. Finally, the changes in HAI definitions during the study may complicate the interpretation of data. However, this is an inherited limitation of any similar trend study and has been partially fixed by excluding diagnoses that are no longer acceptable such as CAUTI with only fungal pathogens.

\section{Conclusion}

In conclusion, 10-year trends of pathogens causing commonly surveyed HAIs showed increasing contribution and resistance of Enterobacteriaceae. However, MDR gram negatives with the exception of Klebsiella and Enterobacter were generally decreasing. Carbapenem resistance was highest in Acinetobacter and Pseudomonas. There was an increasing VRE trend but stable or slightly decreasing MRSA trend during the study. The increasing trends of both CRE and VRE can be at least partially explained by the extensive use of broad-spectrum antimicrobials such as carbapenems, piperacillin/tazobactam, and vancomycin that has been recently documented in our patients [34]. These findings may highlight the need for effective antimicrobial stewardship programs, focusing on education, restrictions, monitoring, and feedback on antimicrobial use and resistance.

\section{Supplementary information}

Supplementary information accompanies this paper at https://doi.org/10. 1186/s13756-020-0678-0.

Additional file 1: Table S1. Characteristics of included hospitals* and healthcare-associated infections (2007-2016). Figure S1. Trends of overall resistance of pathogens causing healthcare-associated in relation to starting implementation of related infection control activities in four MNGHA hospitals in Saudi Arabia (2007-2016).

\section{Acknowledgements}

Not applicable.

\section{Authors' contributions}

$H B, A E s$, and MAs contributed to data analysis, data interpretation, and writing. AA, WA, AEg, SAj, and SAmu contributed to data writing and study design. YA, SAq, HBB, MAg, and SAmo contributed to writing and literature search. All authors read and approved the final manuscript.

\section{Funding}

Not applicable.

Availability of data and materials

Available upon request.

Ethics approval and consent to participate

King Abdullah International Medical Research Center (KAIMRC) waived IRB ethics approval because no identifying patient information was used during this study. No names, patient numbers, photos, person statements, etc. were used during this study.

\section{Consent for publication}

Not applicable.

\section{Competing interests}

The authors declare that they have no competing interests.

\section{Author details}

${ }^{1}$ Infection Prevention and Control Department, King Abdulaziz Medical City (KAMC), Ministry of National Guard Health Affairs (MNGHA), Riyadh, Saudi

Arabia. ${ }^{2}$ King Saud bin Abdulaziz University for Health Sciences, Riyadh, Saudi Arabia. ${ }^{3}$ King Abdullah International Medical Research Center, Riyadh, Saudi Arabia. ${ }^{4}$ Community Medicine Department, Faculty of Medicine, Mansoura University, Mansoura, Egypt. ${ }^{5}$ Infection Prevention and Control Department, KAMC, MNGHA, Jeddah, Saudi Arabia. ${ }^{6}$ Infection Prevention and Control Department, Imam Abdulrahman bin Faisal Hospital, MNGHA, Dammam, Saudi Arabia. ${ }^{7}$ Infection Prevention and Control Department, King Abdulaziz Hospital, MNGHA, Al hassa, Saudi Arabia. ${ }^{8}$ Department of Pathology Medicine, KAMC, MNGHA, Riyadh, Saudi Arabia. ${ }^{9}$ Department of Critical Care Medicine, KAMC, MNGHA, Riyadh, Saudi Arabia. ${ }^{10}$ Department of Medicine, KAMC, MNGHA, Riyadh, Saudi Arabia. ${ }^{11}$ Department of Surgery, KAMC, MNGHA, Riyadh, Saudi Arabia.

Received: 14 October 2019 Accepted: 9 January 2020

Published online: 30 January 2020

\section{References}

1. Rosenthal VD, Maki DG, Mehta Y, Leblebicioglu H, Memish ZA, Al-Mousa HH, Balkhy H, Hu B, Alvarez-Moreno C, Medeiros EA, et al. International Nosocomial Infection Control Consortiu (INICC) report, data summary of 43 countries for 2007-2012. Device-associated module. Am J Infect Control. 2014:42(9):942-56

2. Zimlichman E, Henderson D, Tamir O, Franz C, Song P, Yamin CK, Keohane C, Denham CR, Bates DW. Health care-associated infections: a meta-analysis of costs and financial impact on the US health care system. JAMA Intern Med. 2013;173(22):2039-46.

3. Cassini A, Plachouras D, Eckmanns T, Abu Sin M, Blank HP, Ducomble T, Haller S, Harder T, Klingeberg A, Sixtensson M, et al. Burden of six healthcare-associated infections on European population health: estimating 
incidence-based disability-adjusted life years through a population prevalence-based Modelling study. PLoS Med. 2016;13(10):e1002150.

4. Giske CG, Monnet DL, Cars O, Carmeli Y. Clinical and economic impact of common multidrug-resistant gram-negative bacilli. Antimicrob Agents Chemother. 2008;52(3):813-21.

5. Cassini A, Hogberg LD, Plachouras D, Quattrocchi A, Hoxha A, Simonsen GS, Colomb-Cotinat M, Kretzschmar ME, Devleesschauwer B, Cecchini M, et al. Attributable deaths and disability-adjusted life-years caused by infections with antibiotic-resistant bacteria in the EU and the European Economic Area in 2015: a population-level modelling analysis. Lancet Infect Dis. 2019; 19(1):56-66.

6. Ng E, Earnest A, Lye DC, Ling ML, Ding Y, Hsu LY. The excess financial burden of multidrug resistance in severe gram-negative infections in Singaporean hospitals. Ann Acad Med Singap. 2012;41(5):189-93.

7. de Kraker MEA, Jarlier V, Monen JCM, Heuer OE, van de Sande N, Grundmann $H$. The changing epidemiology of bacteraemias in Europe: trends from the European antimicrobial resistance surveillance system. Clin Microbiol Infect. 2013;19(9):860-8.

8. Durdu B, Kritsotakis El, Lee ACK, Torun P, Hakyemez IN, Gultepe B, Aslan T. Temporal trends and patterns in antimicrobial-resistant gram-negative bacteria implicated in intensive care unit-acquired infections: a cohortbased surveillance study in Istanbul, Turkey. J Glob Antimicrob Resist. 2018; 14:190-6.

9. Chazan B, Raz R, Teitler N, Nitzan O, Edelstein H, Colodner R. Epidemiology and susceptibility to antimicrobials in community, hospital and long-term care facility bacteremia in northern Israel: a 6 year surveillance. Isr Med Assoc J. 2009;11(10):592-7.

10. Lai CC, Chu CC, Cheng A, Huang YT, Hsueh PR. Correlation between antimicrobial consumption and incidence of health-care-associated infections due to methicillin-resistant Staphylococcus aureus and vancomycin-resistant Enterococci at a university hospital in Taiwan from 2000 to 2010. J Microbiol Immunol Infect. 2015;48(4):431-6.

11. Lai CC, Wang CY, Chu CC, Tan CK, Lu CL, Lee YC, Huang YT, Lee PI, Hsueh PR. Correlation between antibiotic consumption and resistance of Gram-negative bacteria causing healthcare-associated infections at a university hospital in Taiwan from 2000 to 2009. J Antimicrob Chemother. 2011;66(6):1374-82.

12. Chiang CH, Pan SC, Yang TS, Matsuda K, Kim HB, Choi YH, Hori S, Wang JT, Sheng $\mathrm{WH}$, Chen $\mathrm{YC}$, et al. Healthcare-associated infections in intensive care units in Taiwan, South Korea, and Japan: recent trends based on national surveillance reports. Antimicrob Resist Infect Control. 2018:7:129.

13. La Fauci V, Costa GB, Arena A, Ventura Spagnolo E, Genovese C, Palamara MA, Squeri R. Trend of MDR-microorganisms isolated from the biological samples of patients with HAl and from the surfaces around that patient. New Microbiol. 2018;41(1):42-6.

14. Fasugba O, Mitchell BG, Mnatzaganian G, Das A, Collignon P, Gardner A. Five-year antimicrobial resistance patterns of urinary Escherichia coli at an Australian tertiary hospital: time series analyses of prevalence data. PLoS One. 2016;11(10):e0164306

15. Balkhy HH, El-Saed A, Al-Abri SS, Alsalman J, Alansari H, Al Maskari Z, E Gammal A, Al Nasser W, AlJardani A, Althaqafi A. Rates of central lineassociated bloodstream infection in tertiary care hospitals in 3 Arabian gulf countries: 6-year surveillance study. Am J Infect Control. 2017;45(5):e49-51.

16. El-Saed A, Al-Jardani A, Althaqafi A, Alansari H, Alsalman J, Al Maskari Z, El Gammal A, Al Nasser W, Al-Abri SS, Balkhy HH. Ventilator-associated pneumonia rates in critical care units in 3 Arabian gulf countries: a 6-year surveillance study. Am J Infect Control. 2016;44(7):794-8.

17. Al Nasser W, El-Saed A, Al-Jardani A, Althaqafi A, Alansari H, Alsalman J, Maskari ZA, El Gammal A, Al-Abri SS, Balkhy HH. Rates of catheter-associated urinary tract infection in tertiary care hospitals in 3 Arabian gulf countries: a 6-year surveillance study. Am J Infect Control. 2016;44(12):1589-94.

18. Horan TC, Andrus M, Dudeck MA. CDC/NHSN surveillance definition of health care-associated infection and criteria for specific types of infections in the acute care setting. Am J Infect Control. 2008;36(5):309-32.

19. National Healthcare Safety Network (NHSN). CDC/NHSN surveillance definitions for specific types of infections, vol. 2013. Atlanta: Division of Healthcare Quality Promotion, National Center for Infectious Diseases; 2013.

20. National Healthcare Safety Network (NHSN). NHSN manual. Patient safety component protocol, vol. 2018. Atlanta: Division of Healthcare Quality Promotion, National Center for Infectious Diseases; 2018.

21. Weiner LM, Webb AK, Limbago B, Dudeck MA, Patel J, Kallen AJ, Edwards $\mathrm{JR}$, Sievert DM. Antimicrobial-resistant pathogens associated with healthcare-associated infections: summary of data reported to the national healthcare safety network at the centers for disease control and prevention, 2011-2014. Infect Control Hosp Epidemiol. 2016;37(11):1288-301.

22. Sievert DM, Ricks P, Edwards JR, Schneider A, Patel J, Srinivasan A, Kallen A, Limbago B, Fridkin S. Antimicrobial-resistant pathogens associated with healthcare-associated infections: summary of data reported to the national healthcare safety network at the centers for disease control and prevention, 2009-2010. Infect Control Hosp Epidemiol. 2013;34(1):1-14.

23. Srinivasan A, Patel JB. Klebsiella pneumoniae carbapenemase-producing organisms: an ounce of prevention really is worth a pound of cure. Infect Control Hosp Epidemiol. 2008;29(12):1107-9.

24. Leavitt A, Navon-Venezia S, Chmelnitsky I, Schwaber MJ, Carmeli Y. Emergence of KPC-2 and KPC-3 in carbapenem-resistant Klebsiella pneumoniae strains in an Israeli hospital. Antimicrob Agents Chemother. 2007;51(8):3026-9.

25. Girmenia C, Serrao A, Canichella M. Epidemiology of Carbapenem resistant Klebsiella pneumoniae infections in Mediterranean countries. Mediterr J Hematol Infect Dis. 2016;8(1):e2016032.

26. Balkhy HH, El-Saed A, Al Johani SM, Francis C, Al-Qahtani AA, Al-Ahdal MN, Altayeb HT, Arabi Y, Alothman A, Sallah M. The epidemiology of the first described carbapenem-resistant Klebsiella pneumoniae outbreak in a tertiary care hospital in Saudi Arabia: how far do we go? Eur J Clin Microbiol Infect Dis. 2012;31(8):1901-9.

27. Uz Zaman T, Aldrees M, Al Johani SM, Alrodayyan M, Aldughashem FA, Balkhy HH. Multi-drug carbapenem-resistant Klebsiella pneumoniae infection carrying the OXA-48 gene and showing variations in outer membrane protein 36 causing an outbreak in a tertiary care hospital in Riyadh, Saudi Arabia. Int J Infect Dis. 2014;28:186-92.

28. Park SO, Liu J, Furuya EY, Larson EL. Carbapenem-resistant Klebsiella pneumoniae infection in three New York city hospitals trended downwards from 2006 to 2014. Open Forum Infect Dis. 2016;3(4):ofw222.

29. Centers for Disease Control and Prevention (CDC): Carbapenem-Resistant Enterobacteriaceae spp. Viewing antibiotic resistance data. 2018. URL: https:// gis.cdc.gov/grasp/PSA/MapView.html. Accessed 10 Jan 2019.

30. Zaman TU, Alrodayyan M, Albladi M, Aldrees M, Siddique MI, Aljohani S, Balkhy $\mathrm{HH}$. Clonal diversity and genetic profiling of antibiotic resistance among multidrug/carbapenem-resistant Klebsiella pneumoniae isolates from a tertiary care hospital in Saudi Arabia. BMC Infect Dis. 2018;18(1):205.

31. Shibl A, Senok A, Memish Z. Infectious diseases in the Arabian Peninsula and Egypt. Clin Microbiol Infect. 2012;18(11):1068-80.

32. Leangapichart T, Gautret P, Griffiths K, Belhouchat K, Memish Z, Raoult D, Rolain JM. Acquisition of a High Diversity of Bacteria during the Hajj Pilgrimage, including Acinetobacter baumannii with blaOXA-72 and Escherichia coli with blaNDM-5 Carbapenemase genes. Antimicrob Agents Chemother. 2016;60(10):5942-8.

33. Enani MA. The antimicrobial stewardship program in Gulf Cooperation Council (GCC) states: insights from a regional survey. J Infect Prev. 2016; 17(1):16-20.

34. Balkhy HH, El-Saed A, El-Metwally A, Arabi YM, Aljohany SM, Al Zaibag M, Baharoon S, Alothman AF. Antimicrobial consumption in five adult intensive care units: a 33-month surveillance study. Antimicrob Resist Infect Control. 2018;7:156.

35. Zowawi HM, Syrmis MW, Kidd TJ, Balkhy HH, Walsh TR, Al Johani SM, Al Jindan RY, Alfaresi M, Ibrahim E, Al-Jardani A, et al. Identification of carbapenem-resistant Pseudomonas aeruginosa in selected hospitals of the Gulf Cooperation Council States: dominance of high-risk clones in the region. J Med Microbiol. 2018;67:846-53.

36. Al-Dorzi HM, El-Saed A, Rishu AH, Balkhy HH, Memish ZA, Arabi YM. The results of a 6-year epidemiologic surveillance for ventilator-associated pneumonia at a tertiary care intensive care unit in Saudi Arabia. Am J Infect Control. 2012:40(9):794-9.

37. El-Saed A, Balkhy HH, Al-Dorzi HM, Khan R, Rishu AH, Arabi YM. Acinetobacter is the most common pathogen associated with late-onset and recurrent ventilator-associated pneumonia in an adult intensive care unit in Saudi Arabia. Int J Infect Dis. 2013;17(9):e696-701.

38. Al-Thaqafy MS, El-Saed A, Arabi YM, Balkhy HH. Association of compliance of ventilator bundle with incidence of ventilator-associated pneumonia and ventilator utilization among critical patients over 4 years. Ann Thorac Med. 2014;9(4):221-6.

39. Ratna A, El-Saed A, Alsaif S, Tannous J, Dagunton N, Balkhy H. Effect of central line bundle implementation on central line-associated bloodstream infection rates in NICU in KSA. Int J Infect Control. 2016;12(2):1-7. 
40. Abdallah M, Al-Saafin M. Overview of prevalence, characteristics, risk factors, resistance, and virulence of vancomycin-resistant enterococci in Saudi Arabia. Microb Drug Resist. 2018;25:350-58.

41. Al-Hamad A, Alfaraj A, Altowaileb J, Al-Shamlan S, Leskafi H, Alsubeikhy F, Abbas $\mathrm{H}$. Incidence and antibiotic susceptibility of MRSA infections in a Saudi Arabian hospital: a 10-year surveillance study. J Infect Dev Ctries. 2018;12:454-61.

42. Alotaibi FE, Bukhari EE. Emergence of Vancomycin-resistant Enterococci at a teaching hospital, Saudi Arabia. Chin Med J. 2017;130(3):340-6.

43. Shorman M, Al-Tawfiq JA. Risk factors associated with vancomycin-resistant Enterococcus in intensive care unit settings in Saudi Arabia. Interdiscip Perspect Infect Dis. 2013;2013:369674.

\section{Publisher's Note}

Springer Nature remains neutral with regard to jurisdictional claims in published maps and institutional affiliations.

Ready to submit your research? Choose BMC and benefit from:

- fast, convenient online submission

- thorough peer review by experienced researchers in your field

- rapid publication on acceptance

- support for research data, including large and complex data types

- gold Open Access which fosters wider collaboration and increased citations

- maximum visibility for your research: over $100 \mathrm{M}$ website views per year

At BMC, research is always in progress.

Learn more biomedcentral.com/submissions 